\title{
The Role of Couselling Psychologists in the Adjustment and Management of Physically Challenged People in Nigerian Community
}

\author{
Bibire Abdulkareem Hussein \\ Department Of Psychology Nigeria Police Academy, Wudil, Kano State
}

\begin{abstract}
It is observed in the past that people have one problem or the other in which they cannot solve or provide remedies on their own be it social, educational, vocational, and psychological. At that point in time those categories of people had gone to other people in the society to solicit for helps and assistance. For this fact, the researcher deem it fit and necessary to investigate whether with the advancement of knowledge, and technology which make the country to be a global village there are professionals or experts that can provide lasting solutions to those problems through the counselling skills and techniques, rather than seeking helps from herbalists or ritualists among others. Importantly, there is need for urgent call to have professionals and experts in counselling that will handle the problems successfully and provide clue or way out to the constraints. Such professionals will utilize their knowledge, experience, wisdom, and skills to handle the social, educational, vocational, and psychological needs of physically challenged people in the society at large.
\end{abstract}

Keywords: Adjustment, Counselling Psychologists, Management, Physically challenged people, Role

\section{Introduction}

Counselling is a special relationship between the counsellor and the client (counselee) with the purpose of helping the client in self-understanding, decision making, choice of desires and problem solving. This is also oriented towards stimulating efficient and effective learning skills, acceptable habits and desirable behaviours in people. According to Gladding (1995) counselling is a dynamic, ever-evolving and exciting profession that deals with human tragedy and possibility in an intensive, personal and caring way. In the same vein, the American Psychological Association, division of counselling psychology committee describes counselling as a process to help people towards overcoming problems to their personal growth wherever this may be encountered as well as achieving optimum. In a situation where people have problems and experienced difficulties and they could not provide remedies to such issues, however, they had to turn to other people for help or assistance or even guidance.

The American Psychological Association (1985) cited in Gesinde (2006) asserted that counselling psychology is " a speciality in the field of psychology whose experts, help people improve their well-being, alleviate their distress, resolve their crises, and increase their ability to solve problems, and make decisions. Counselling Psychologists utilize scientific approaches in their development of solutions to the variety of human problems resulting from interactions of intra-personal, inter-personal, and environmental forces. Counselling Psychologists conduct research, apply interventions, and evaluate services in order to stimulate personal and group development, and evaluate services. Services in order to stimulate personal and group development, and prevent and remedy developmental, educational, social and vocational problems and adheres to strict standards and ethics".

Counselling Psychologists involve in wide range of activities, the psychologists activity in different situations or circumstances depending on the kind and nature of services expected and the number of the client or counselee handled. For instance, some of the counselling psychologist activities include the following:

(1)Community mental health centres;

(2)Teaching in the institutions of learning;

(3)Employment agencies;

(4)Research centres;

(5)Marriage and family centres;

(6)Rehabilitation agencies;

(7)Industrial organization; and

(8)Counselling firms and private practice. (Abiodun and Tola, 2006)

According to Adeyemo (2002) counselling psychologists' main responsibility in organatiosational settings is the provision of human resources services which includes:

Defining work roles and relationships; 
(2) Staffing the structure with suitable people;

(3) Designing an effective organizational structure; and securing optimum working arrangement.

Physically challenged individuals are the category of people who deviate from what is considered to be normal or average in physical appearance. These categories of people need counselling services.

According to Adeniran (1995), Mallum (2000), and Owuamanam (2005) cited in Anthonia (2007) the goals and objective of counselling in society include the following;

(1) To help individuals in making appropriate and satisfying personal, social, educational, and vocational choices.

(2) To guide individuals as early as possible to require positive image of self through self understanding, self direction and acquisition of problem-solving of the child's problem and accept the child with his or her disability, northing much will be done as regards taking positive steps towards seeking solution to the child's problems.

\section{Adjustment Needs for Physically Challenged People}

A physically challenged person is expected to live with all the consequences of his or her challenge (personal and social) over time (Ozoji, 2003). The individual has to come to realise the fact that he is permanently different from he was prior to challenge. These realizations call for a more concrete approach that would enable the individual, as Ozoji observed that cope with and withstand the vicissitudes of pattern determined by challenge. According to Dada (2007) adjustment as man's efforts successfully and unsuccessfully to deal with life in the face of environmental demands, internal pressure and human potentialities. Adjustment entails the achievement of a psychological rehabilitation by which one is brought to an emotional stake akin to pre-challenge stage. It is also implies an emotional and intellectual acceptance of loss. Omolehin (2006) submitted that adjustment is an achievement emphasizes quality or efficacy of adjustment, while adjustment as a process describes the process by which an individual adjust in his external environment. Adjustment to physically challenged person connotes acceptances of the condition of challenge without feeling shameful about it (Ozoji, 2003).

\subsection{Phases of Adjustment}

Counselling Psychologists see adjustment as a concept which cannot be achieved immediately. But it comes in gradual processes. These phases include:
Denial phase
(2) Anger phase
Depression phase
(5) Acceptance phase
(3) Bargaining phase

(1)Denial phase: This stage involves a distortion of reality in the face of overwhelming stress and anxiety. It is also a generally accepted human reaction to unpleasant news. Denial is believed to be self preserving in the sense that it gives an individual time to slowly process and acknowledge in one massive close or reality could lead to personality disintegration to deny the magnitude of loss. The reality is permitted to sink into the person only gradually, beginning with denial. However, prolonged denial is not helpful for it delays the process of adjustment.

(2) Anger: This is the second phase of reaction to knowledge of terminal illness. The person views his loss as unfair and finds it difficult to image a future, given his altered status. The value of recognizing anger as a stage is to enable workers and relations understand client's anger which is legitimate.

(3) Bargaining: This is the third phase of adjustment here the person now realises that angry approach is unhelpful and so would look for other acceptable way and means of getting over the angry feelings. In most cases, the bargains are made with the client's God. For example,' Oh God, if I go through this physical therapy I promise to be a faithful groom and so on. This phase provides means for realising psychological problems, particularly, those related to guilt.

(4) Depression: This is the fourth phase of adjustment this connotes the rehabilitation process; depression is the rule rather than the exception. Experts say that absence of signs of depression in a recently physically challenged individual suggests that something is psychologically amiss. For instance, it may be an evidence of gross denial, psychosis or brain damage. This stage is critical to the adjustment process and should be handled with care. The physically challenged person must be allowed this legitimate emotion to the depths of it so that he can realize the magnitude of his loss before he can truly adjust to his new status.

(5) Acceptance: This is the final phase of adjustment, psychologists submitted that adjustment takes place over time, and that is does not run a smooth course. At whatever stage we meet to recognize this and assist the person to next stage until the final stage is reached (Ozoji, 2003, 2005 cited in Ajobiewe, 2008). 


\section{Role of Counselling Psychologists in the management of physically Challenged Students}

The provisions of counselling services to physically challenged people help in fostering stable growth and development in teaching and learning. The counselling psychologists could therefore provide relevant and adequate services to the category of students in order to assist them benefit adequately from the societal values. Counsellor should provide an assistance hands to physically challenged children in the early diagnosis design of individual prescriptive programmes that outline the learning sequence of a given individual. Provision of orientation service is highly required for physically challenged students. Orientation programme helps students to get familiar with a new environment and to adapt to the demands of the school. It is also assists the students, the teachers and the other school personnel to know and understand themselves. Since the counsellors usually have close inter personal relationship with physically challenged students, they should provide placement and referral services. They should also provide relevant information in the areas of educational and vocational as well as personal-social information to the physically challenged individuals (Ezere, 2004).

The member of the society need to be enlightened on ways by which they can provide love, care and useful facilities for physically challenged people in order to operate efficiently and effectively. Counselling psychologists should counsel and guide the members of the society on the need to avoid negative remarks, which could endanger or injure the physically challenged ones, lower their morale and make them feel inferior and unwanted. Parents and significant others need to emphasize the strengths of the physically challenged children rather than their weakness. Thus, there is ability in disability.

\subsection{Social Need}

Most of the physically challenged individuals encountered difficulty in coming to terms with their challenges. In the light of the above, such constraints such as isolation, loss of confidence in self, poor coordination, over dependency and etc set in. While considering the said objectives above. It becomes necessary that people with physically challenged are guided to acquire social skills, necessary for their personality adjustment and development. To attain this, depends on proper communication within the society, handled in such a way that social relationship and interaction of these people within the home, school and community would become reinforcing or rewarding experiences for physically challenged people in the society (Hallahan and Kauffman, 2003). It should be stress here that the development of behavioural problems of physically challenged individuals depends to a great extent on how well those in their society accept them and their problem. Similarly, another considering issue in this context is that of addressing or labelling that is physically challenged people must not be called by their identity rather than by their names negative address or label leads to withdrawal, intimidation, feel same, feel inferior and feeling of failure. Therefore, counselling psychologists need to address this and request that the focus should be on the individual's abilities, capabilities or potentials rather than the challenged. Developing positive self esteem in the physically challenged people requires the counsellor to act as a role model. In that wise the counselling psychologists need to utilize different techniques, methods and application of counselling psychology where need be. Similarly, self care or self management these expects need to work in collaboration with parents and other professional bodies to ensure that people with this challenge acquire the skill of self management and self care. This can be done by helping physically challenged persons to favourable attitudes towards acceptable norms and standards and ensuring that they appreciate the importance of self- care (West wood, 1987 cited in Anthonia, 2007).

\subsection{Educational Need}

In social environment physically challenged people like all other individuals in terms of acquiring knowledge and education. Reason is thus, it is the right of every child to have access to education, education for all (NPE, 2004). As far as those children have the potentials; they should be given appropriates placement therefore, it is the responsibility of counselling psychologists to see that physically challenged students during their course of study are helped early enough to make correct choice of subjects, courses and career. In this context, they must consider the peculiarity of this category of persons, the limitations, problems or hindrances. The uniqueness of physically challenged persons (strength and weakness) and area of interest should be considered. In other words, different from his potentials i.e. intellectual ability and area of interest, physically challenged students still need counselling in career choice exploration. More importantly, the counsellors should have the responsibility to advice entire staff including principals in different schools to supervise teaching and learning on occasional basis (Owuamanam, 2005).

\subsection{Vocational Need}

The vocational need for physically challenged people it is the responsibility of the counsellor to stress the need for appropriate vocational placement. So the abilities and interest must be equally be considered. The counsellor psychologists should explain and address the implication of wrong placement. He should also explain 
that vocational skills could be acquired outside organised home as well. It could be acquired from the "'roadside work-men in their workshops or in the market place. Counsellor should serve as a link between the family, school, vocational training counters, professional bodies and organisations (Glodoff \& Kopowecz, 1990 cited in Anthonia, 2007).

\subsection{Psychological Need}

Parents are the most considerable factor in the development of psychological aspects of their children. The counsellors and parents should collaborate their efforts to achieve the success of this need of the children. Physically challenged individuals need to be psychologically and emotionally balanced and this need has to be in the light of psychological treatment been received from counselling psychologists.

\section{Conclusion and Recommendations}

On the basis of the literature reviewed, the following recommendations were made:

(1) Counselling psychologists should expedite actions and efforts at enlighten the general public and specifically the physically challenged people on their relevance and value in the society in terms of social, educational, vocational, and psychological. So they should not see themselves as challenge to the society of as passive member of the society but as active or functional peer of it because there is ability in disability.

(2) More importantly, physically challenged individuals should have it at their mind that they have equal rights and privileges with other people in the society. Therefore, they should intensify their efforts to enjoy the same privileges as enjoyed by non physically challenged individuals.

(3) It is also recommended that there should be adequate provision of counselling services for parents of physically challenged children often and often. This is important because parents contribute meaningfully and positively to the development of their children.

(4) It is recommended that counselling psychologists should work in affiliation with other professional bodies, agencies and experts in order to provide sufficient and effective services to the physically challenged people.

\section{References}

[1]. ST Gladding, Counselling, A Comprehensive Profession ( $3^{\text {rd }}$ Ed) New Jersey. Prentice Hall. 1995

[2]. American Psychological Association, Minutes of Mid winter Executive Committee Meeting Chicago1985

[3]. A.M Gesinde, Psychology of child development, Ibadan Foludex Press Ltd. American Psychological Association, Division of Counselling psychology committee on Definition (1956). Counselling psychology as a special American psychologists it, 282-285 2001

[4]. M.G Abiodun, \& O. Tola, Differential Perception of Counselling Psychologists' Duties to Oyo state Broadcasting cooperation. The Nigerian Journal of Guidance and Counselling. An International Journal 2 (1) ISSN 0794. 2006

[5]. D.A Adeyemo, Counselling Psychology in work organisations. In J.O Akinboye (Ed.) Psychological Principles for Success in Life and Workplace. 102-113: Ibadan: Stilling. Horden publishers (Nig.) Limited. 2002

[6]. G. Adeniran, Handbook of Guidance and Counselling. Ado Ekiti: Hope paper mills Ltd. 1995

[7]. A.Y Mallam, Guidance and Counselling. Beginners guide. Jos Deka Enterprises (Nig.) 2000

[8]. T.O Owuamanam, The Role of the Counsellor and other School Personnel in Providing Quality Education in Nigerians Schools. The Nigerian Journal of Guidance and Counselling, 10 (1), 12-21 2005

[9]. A. Anthonia, Counselling People with Special Needs in Rural Settings. The Nigerian Journal of Guidance ISSN 0794-08312007

[10]. E.D Ozodi, The Imperatives of Special Education attitudes, Jos Journal of Education 6 (2), 16-26 2003

[11]. E.D Ozodi, Special Education for Beginners Professionals (2 ${ }^{\text {nd }}$ Ed.) Jos; Delta publications. 2003

[12]. M.F. Dada, Problems Counselling Needs and Coping Strategies of Institutionalised African Refugees in Nigeria. Unpublished doctoral dissertation, University of Ilorin, Ilorin, Nigeria. 2007

[13]. C.O Omolewin. Adjustment Needs, Supports Systems and Coping Strategies of Orphans in Nigeria Orphanages. Unpublished doctoral dissertation, university of Ilorin, Ilorin, Nigeria. 2006

[14]. J.A. Ajobiewe, Problems Adjustment Needs and coping Strategies of the Visually Impaired in Rehabilitation Centres in Nigeria 2008

[15]. M.O Esene, Learning, Disabilities and Learning Problems in Schools. Indemac Publishers (Nig.) Ltd Ilorin, Kwara State, Nigeria. 2004

[16]. D.P Hallaham, \& J.M Kauffmans, Exceptional Learners Introduction to Special Education; Columbus Ally and Bacon. 2003

[17]. National Policy on Education, cited in Anthonia A Counselling People with special Needs in Rural Setting. The Nigerian Journal of Guidance and Counselling. An international Journal ISSN 0794-0831 2004, 2007

[18]. H. Glosoff. \& C. Kofoewiez. Children Achieving Potential. An Introduction to Elementary School Counselling and State Legislature and the American Association for Counselling and Development. 1990 